\title{
15
}

\section{Avenues for Future Research}

The point of departure for this book is the need for business model innovation that can lead to more business models that are both sustainable and profitable. In the first part of the book, we argued why such business models are needed, we discussed the overarching goal of aligning sustainability performance and financial performance and we illuminated the challenges related to succeeding with such business model innovations. In the second part of the book, we developed the RESTART framework that sheds light on seven characteristics that we propose will be important in the transition toward more sustainable business models. However, in order to enable such a green transition, much more knowledge is needed on the nature and characteristics of these kinds of business models. Moreover, we need knowledge of the mechanisms through which they may create value for stakeholders while ensuring that they restore and regenerate, rather than break down, societal and natural capital. Finally, we need empirical insight into the managerial, leadership-related and organizational capabilities and governance structures that can support the implementation of such business models.

In this chapter, we discuss avenues for future research on these issues. This book aims to contribute to the research agenda for sustainable 
business model innovation. For this reason, we have explored-both from the conceptual and empirical points of view-the nature and characteristics of such business models and how they might be designed and innovated. In these final sections of the book, we aim to articulate some of the implications the discussions in this book have for future research. What are the unanswered questions? Where is the fertile soil for empirical investigation? What might be valuable research designs and methodological approaches to shed more light on these issues? And where do we see the field going in the coming years?

\subsection{Mind the Gap!}

Issues related to corporate conduct and misconduct, in general, and corporate responsibility, in particular, have been studied for a very long time. Even Aristotle discussed the problems related to value creation for profits, which he coined "chrematisike" (see, e.g., Solomon 1992), but the roots of the current discussion of corporate responsibilities mostly arose in the twentieth century (cf. Carroll 2008). While there was some academic discussion about corporate responsibility with regard to corporate crime in the early 1900s, the conversation on corporate social responsibility began to converge on some of the issues still relevant today during the post-World War II period (see, e.g., Bowen 1953; Davis 1960; Katz 1960; Frederick 1960; Eells and Walton 1969). The seminal piece by Friedman (1970) and the equally important response more than a decade later by Freeman (1984) laid the foundations for the academic and practical discussion about the business case of sustainability that is still ongoing today.

As reviewed in the second part of the book, there is a comprehensive literature investigating the so-called business case for sustainability or in the language used in this book-the attempt to align sustainability performance and financial performance. One would arguably still consider this literature inconclusive-it depends on the time horizon measured (Wang and Bansal 2012), the way outcome variables are construed (see, e.g., Orlitzky et al. 2003; Waddock and Graves 1997) and even the context in which the empirical investigations are conducted (cf. Strand 2017; see also Eccles et al. 2015). The right question, perhaps, is not whether 
investing in sustainability pays, but rather through which mechanisms sustainability efforts may lead to improved business performance. In essence, it involves thinking about the relationship between business models and (positive and negative) externalities and how attending to the right externalities at the right time with the right means can translate into benefits for the company's product and/or factor markets (Jørgensen and Pedersen 2015). Sustainability efforts are not a one-size-fits-all phenomenon, and the heterogeneity in which sustainability issues are most important and which efforts are best suited to address them is crucial to corporate sustainability efforts in practice.

The perhaps most convincing attempts to study the relationship between sustainability and business performance are characterized by exactly such precision and focus. Examples include Khan et al. (2016), who study the relationship between companies' prioritization of more and less material sustainability concerns and financial performance; Edmans (2012), who investigates the link between social performance, job satisfaction and firm value; Flammer and Kacperczyk (2015), who demonstrate a positive relationship between stakeholder orientation and the company's innovativeness; and Kang et al. (2016), who manage to distinguish empirically between different mechanisms through which sustainability efforts translate into business performance.

Going forward, we believe that these are exactly the kinds of studies we need to proliferate. Focused empirical investigation of such mechanisms, ideally also with experimental interventions, can considerably further our understanding of what it takes to align sustainability performance and financial performance in practice. In the following, we aim to point out fruitful avenues for further research based on the framework developed in this book. In doing so, we share parts of our own research agenda, but we simultaneously invite all fellow researchers to join us in investigating these relationships. The research gap in corporate sustainability research is of course very comprehensive, and too far-reaching than what can be meaningfully outlined in this chapter. Therefore, our goal is mainly to outline the empirical investigations that can serve as a continuation of the work presented in this book, specifically on the phenomenon of sustainable business model innovation. 


\subsection{Research Designs and Methodologies}

Our framework does not assume any specific research designs or empirical strategies. Corporate sustainability research is highly interdisciplinary and heterogeneous with regard to both theoretical and methodological approaches. As documented by Bass and Milosevic (2016), qualitative research designs have increased significantly in business and society research, and such research designs are arguably well suited to address numerous issues in sustainability research that are as yet ill-defined and "messy" phenomena from a definitional standpoint (see also Eisenhardt et al. 2016). Predominantly, however, there have been considerable amounts of studies using quantitative approaches, including studies of the business case, studies that investigate consumer behavior related to sustainability efforts, studies informed by moral and social psychology that investigate decision-making in sustainability efforts and so on (see, e.g., Lockett et al. 2006 for an overview).

In an inspiring "call to arms", Crane et al. (2018) reviewed the field of business and society research and made a broad distinction between "quants" and "poets". That is, they distinguish between the mainly quantitative research approaches of the "quants", the mainly qualitative research approaches of the "poets" and the mixed-methods approaches of the "quants and poets". Crane et al. (2018) look into the crystal ball with regard to future methodological development. They emphasize that future studies need to "respond to the real-world problems and challenges that lie ahead", that they need to be able to shed light on issues that "are systemic in nature" and therefore span across single cases and that there is "a need for more theoretically informed empirical research". In order to achieve such research designs, the authors argue that there is need for more mixed-methods studies, more research based on field data and more "adventurous and robust" action research.

As we will show in the following, we share many of the viewpoints proposed by Crane et al. (2018). As is evident from the present work, we are strong believers in research conducted in proximity to, and collaboration with, companies. Our own empirical efforts that underlie this work began with a series of qualitative studies in the mid-2000s, after which we conducted some surveys on broad samples of companies. Increasingly, 
however, we concluded that in order to properly investigate the sustainability efforts of companies, we needed an empirical strategy that allowed us to get closer to the phenomena we wanted to understand.

For this reason, we are currently in the process of conducting field experiments with existing corporate partners and planning new field experiments to investigate the phenomena and relationships discussed in this book. With many of these companies, we simultaneously engage in innovation processes, sometimes using the tools from The Business Model RESTARTer. This is because designing field experiments requires a very intimate understanding of the context in which the investigation takes place, and what are the most important relationships to be studied and outcomes to be measured. Field experiments are a specific subset of experimental studies that are characterized by being conducted in the field in which decision makers and organizational members actually carry out their choices and activities (cf. Harrison and List 2004). This allows for a unique combination of realism and control in empirical investigation (Levitt and List 2007). Not at least, field experiments are desirable due to the possibility of randomization in the field, which can allow for better identification of cause-and-effect relationships (see, e.g., Levitt and List 2009). Delmas and Aragon-Correa (2016) argued that such research designs are particularly suited to study "microanalyses of employee or consumer behavior as they relate to sustainability". However, as demonstrated by Chatterji et al. (2016), this methodological approach can also allow for interventions and investigations related to firm-level outcomes. As we will show below, we believe that many important phenomena discussed in this book can be successfully studied by means of field experimental designs - a relatively novel approach in the field of corporate sustainability research (cf. Delmas and Aragon-Correa 2016; Crane et al. 2018).

However, we do not believe that all phenomena in sustainable business model innovation are equally well suited for experimental studies. We share the enthusiasm of Crane et al. (2018) for action-based methods, and as shown in this book, we already work in research projects with companies in which we also serve as advisors and therefore "actors" in the empirical reality we are trying to map. In the case study on Scanship elsewhere in this book, this role is evident. However, a combination of 
empirical approaches-for instance, a combination of action-based research and field experiments developed as the culmination of such a process - seem promising in this regard. Importantly, it is necessary to move beyond mere description or accounts of companies' efforts to become more sustainable, which can be a limitation of some pure actionbased studies.

Finally, we believe that there is considerable need for further qualitative work on many of the issues covered in this book. In particular, comparative case studies between different kinds of business models, different kinds of sustainability efforts and the fit of various sustainability efforts in different contexts (e.g., industrial, geographical and cultural) seem promising. Moreover, in-depth interview studies, observational studies and other approaches that can shed light on microprocesses of sustainability work can contribute important insights that are valuable for the attempt to design more sustainable business models, and-perhaps in particular-implementing them in practice in organizational settings.

In the following section, we try to formulate a specific research agenda for the seven components of the RESTART framework outlined in the second part of the book. We consider this agenda work in progress, and we invite all our colleagues to join us in implementing it in practice, using manifold empirical strategies, in various contexts and for different purposes.

\subsection{A RESTART Research Agenda}

As outlined in the second part of the book, we consider the seven components of the RESTART framework to be simultaneous developments and factors in the movement toward more sustainable business models. This implies that they are inter-connected, and we believe that in order to succeed with each of them in practice, more knowledge is needed.

With regard to redesign, there is already a considerable literature detailing the need for further research on business model innovation in general. For instance, Foss and Saebi (2017) emphasized the need for studies investigating four main issues: (1) defining and dimensionalizing the business model innovation construct, (2) identifying antecedents and 
outcomes of business model innovation, (3) investigating contingency and moderating variables and (4) mapping the boundary conditions of the concept (see also Zott et al. 2011). In a review that is one step closer to the scope of this book, Boons and Lüdeke-Freund (2013) formulated a research agenda for sustainable innovation. They argued that there is a need for more investigation of sustainable system innovations and their relation to business success (cf. Crane et al. 2018), as well as an investigation of the degree to which sustainable business model innovations actually deliver on sustainability-related outcomes.

Informed by these reviews and by our work on redesign thus far, we believe that future studies should investigate the mechanisms underlying successful sustainability improvements that contribute to, or enable, business model innovation. That is, what characterizes business models wherein sustainability improvements are central elements in the new business model that are value-enhancing for customers or other stakeholders? Moreover, we believe that piloting or A/B-testing-as carried out by companies that conduct business experiments (see, e.g., Anderson 2011; Davenport 2009) — can serve as the basis for potential field experiments that can compare the viability of rival business models during the "reinvent" phase (cf. the chapter on The Business Model RESTARTer). Implementing a new business model is a high-risk endeavor and using experimental methodology to test and compare business models prior to redesign seems a particularly high-value research contribution. However, a crucial challenge from the point of view of research design, in general, and generalizability of results, in particular, is that the experiment is designed in a manner that is not too specific to the case company in question.

This leads us to research opportunities related to experimentation itself. This implies studying the experimentation processes of companies and can provide insight into success factors in carrying out such efforts in practice. Bocken et al. (2017) conducted a study on how such experimental efforts aided the transition to circularity in an international clothing company. Crucial questions related to experimentation in practice include how to cultivate a culture for experimentation in a company as well as how to identify and design key performance indicators that can be measured by means of well-designed business experiments. 
In addition, a particularly tempting proposition is to conduct a "metaexperimental" study, that is, to conduct an experiment on business experimentation. For instance, investigating two different approaches to business model experimentation, or two different uses of key performance indicators, could reveal success factors in carrying out such business experiments in practice. Qualitative and quantitative studies of barriers to such experimentation could also provide valuable insights.

Regarding the three components in the center of the frameworkservice-logic, the circular economy and alliances - there is of course considerable work done as well as plentiful calls for further research. However, for the present purposes, we emphasize the need for further research into how these three phenomena can be drivers of, or constituent parts of, more sustainable business models.

With regard to service-logic, there are exciting research opportunities tied to the boundary conditions of service-based business models for sustainability. Business models based on access or functionality rather than ownership (see, e.g., Bocken et al. 2014) are widely considered to be important to promote more sustainable consumption. An interesting question is what distinguishes products that consumers are willing to consume through such business models from the products that consumers still prefer to own, even when access-based models emerge. Such boundary conditions are important for understanding the scope and potential for such business models across product categories and industries. A second main theme that carries great promise is product-service systems, and in particular the potential for adding new services "on top of" the main value proposition when transitioning to a product-service system business model (see, e.g., Mont and Tukker 2006; Tukker and Tischner 2006). This issue is central to the financial viability of such business models and the ability of companies to sustain them over time.

With regard to the circular economy, many research efforts are needed to understand how circular business models can function and succeed as an alternative to linear, "business-as-usual" models. In fact, we have already commenced a couple of research projects aimed at investigating circular business models, one of which is introduced in the case study chapter on Orkla and BIR elsewhere in the book. The first main theme we see as promising relates to new distribution channels in the circular 
economy. The need for take-back of old products, materials and components, as well as the need for package-reducing solutions, such as "refilleries", are central to make the infrastructure of circular business model function (cf. Bocken et al. 2016). A central research question in this regard is what types of distribution channels are more and less attractive to customers and users and which are the barriers for adoption of such distribution channels.

A second, and highly important, topic for research in relation to circular business models relates to payment models. Anecdotal evidence suggests that one of the challenges for many circular business models thus far is to generate sufficient revenue over time, which, for instance, some leasing-based apparel business models (e.g., Filippa K) have experienced. Payment models are foundational to business models, and they need to be adapted to the characteristics of customers, markets and the competitive landscape. Thus, investigating various forms of payment models for different circular business models is likely to yield valuable insights for companies trying to unlock the profit potential in such business models.

A final promising research topic related to circular business models is to investigate the contingencies between different types of circular business models and the industries in which they are used. For instance, are there systematic differences in the viability of different circular business models_-as an example, a leasing-based model versus a refurbishingoriented model versus a sharing model—depending on the industry? Insights into the fit between business model design and industry characteristics seem a promising, although challenging, avenue for research.

With regard to alliances, there is also plenty of fertile ground for empirical investigation. As discussed by Kiron et al. (2015), CEOs all over the world state that collaboration for sustainability has become increasingly important for their companies, but at the same time, very few of them perceive their collaborative efforts to improve sustainabilityrelated outcomes as being successful. As pointed out by Selsky and Parker (2005), cross-sector collaborations for social (and, one would add, environmental) purposes are increasingly widespread but pose particular challenges with regard to partnership design and implementation.

One promising avenue for research on this issue relates to the challenge of developing collaborative cross-sector business models at the bottom of 
the pyramid - a topic we have discussed previously in the book. Such a collaborative process involves the alignment of objectives across organizations, the leveraging of resources and capabilities of the different partners of the collaboration and the attempt to build a distribution channel for products and services in a market with considerable needs, but where infrastructural, human capital and financial conditions render distribution challenging. All of these issues are ripe for empirical exploration, and the knowledge gap with regard to business models for the bottom of the pyramid, and the collaboration that can enable such business models, is considerable. Moreover, the interrelated set of topics listed above is not only relevant in the specific case of business models at the bottom of the pyramid. The attempts to align the objectives of alliance partners in a collaboration for sustainability or the leveraging of resources across organizational boundaries in such alliances are more generally important topics for empirical investigation.

The latter two components of the RESTART framework—results and three-dimensionality —offer very interesting and potentially impactful research. As demonstrated by, for example, Eccles et al. (2015), organizational and governance characteristics related to management control systems are highly important for successful design and implementation of sustainability efforts. Not at least, the research on materiality assessments and strategic prioritization, which is steadily growing, has shown great promise (cf. Khan et al. 2016). In prior work, we have empirically investigated such characteristics of companies in the Norwegian setting (Gulbrandsen et al. 2015, 2017), and our findings reveal that, thus far, the systematic use of key performance indicators, incentives for sustainability performance and so on are quite limited.

With regard to results, future studies should continue the important work being done on materiality assessments. One interesting approach would be to investigate further the relationship between stakeholder management as conducted by means of materiality assessments on the one hand and the development and use of key performance indicators related to material concerns on the other. A related topic of potentially high value is the role played by chief sustainability officers and similar organizational roles in such work (see, e.g., Strand 2013), which could contribute to the understanding of organizational microprocesses underlying successful stakeholder management. 
With regard to three-dimensionality, there are several interesting strands of potential research. One interesting approach from a management control point of view would be to investigate how companies generate and use relevant and timely information on sustainability performance in order to inform ongoing sustainability efforts. In an age of digitalization, it will be interesting to follow if - and, if so, how-the use of real-time information for decision-making purposes will emerge. There has been a lot of emphasis on sustainability reporting and accounting in recent years, but one would expect that new technologies for data management and analysis are likely to create novel forms of real-time information systems that may even replace conventional sustainability reporting systems, both for internal and external purposes.

A topic related to three-dimensionality that is fruitful for field experimental investigation is the use of incentives (financial or non-pecuniary) to stimulate sustainability performance at the individual, unit and corporate level. For instance, a study could build on an intervention whereby different incentive schemes were tested and compared to a control condition absent of incentives. Such empirical investigation could provide valuable insights into the specific and differential effects of various incentive schemes for sustainability performance, which could be valuable in corporate attempts to drive such performance. Finally, comparative case studies and other empirical designs could also provide valuable insights into different organizational designs for driving sustainability performance-both in the specific case of how sustainability work is integrated in the organization (separate unit vs. embedded approach) and with regard to how the work itself is organized.

\subsection{An Ocean of Opportunities}

In the preceding sections, we have given an overview of a vast set of research opportunities in the vaguely defined field that comprises research on sustainable business model innovation. While this overview only scratches the surface of the possibilities for exciting research, it at least points out a set of potentially fruitful ways to empirically explore the RESTART framework developed in the second part of this book. 
A final note on this overview is related to the rapidly changing opportunity space that follows from ever-increasing amounts of data combined with increasingly powerful statistical methods based on deep learning and so on. It is argued by many that we are entering an "inductive revolution", meaning that the traditional hypothesis-developing and -testing approach of research will be replaced by methods whereby algorithms explore vast amounts of data to find patterns and relationships that can provide valuable insights (see, e.g., Sullivan and Zutavern 2017). For most researchers, it is hard to envision how such a future of empirical investigation will look, what it will imply for the role of the researcher and what constitutes good research questions. However, we are confident that such developments will also shape the future of corporate sustainability research.

More generally, attempting to do research, teach and write about sustainable business model innovation in the age of digitalization is like drawing a map of a landscape that changes quickly and continuously. For this reason, we expect-and hope-that this overview of avenues for future research will have a relatively short half-life. Regardless, we hope that our account of research opportunities reviewed here can stimulate interesting research projects and-perhaps even more importantly-further research ideas not yet conceived.

\section{References}

Anderson, E. T. (2011). A step-by-step guide to smart business experiments. Development and Learning in Organizations: An International Journal, 25(6). https://www.emeraldinsight.com/doi/full/10.1108/dlo.2011.08125faa.011.

Bass, A. E., \& Milosevic, I. (2016). The ethnographic method in CSR research: The role and importance of methodological fit. Business \& Society. https:// doi.org/10.1177/0007650316648666.

Bocken, N., Miller, K., Weissbrod, I., Holgado, M., \& Evans, S. (2017). Business Model Experimentation for Circularity: Driving sustainability in a large international clothing retailer. Economics and Policy of Energy and the Environment (EPEE).

Bocken, N. M., de Pauw, I., Bakker, C., \& van der Grinten, B. (2016). Product design and business model strategies for a circular economy. Journal of Industrial and Production Engineering, 33(5), 308-320. 
Bocken, N. M. P., Short, S. W., Rana, P., \& Evans, S. (2014). A literature and practice review to develop sustainable business model archetypes. Journal of Cleaner Production, 65, 42-56.

Boons, F., \& Lüdeke-Freund, F. (2013). Business models for sustainable innovation: State-of-the-art and steps towards a research agenda. Journal of Cleaner Production, 45, 9-19.

Bowen, H. R. (1953). Social responsibilities of the businessman. New York, NY: Harper \& Row.

Carroll, A. B. (2008). A history of corporate social responsibility: Concepts and practices. In A. Crane et al. (Eds.), The Oxford handbook of corporate social responsibility (pp. 19-46). Oxford: Oxford University Press.

Chatterji, A. K., Findley, M., Jensen, N. M., Meier, S., \& Nielson, D. (2016). Field experiments in strategy research. Strategic Management Journal, 37(1), $116-132$.

Crane, A., Henriques, I., \& Husted, B. W. (2018). Quants and poets: Advancing methods and methodologies in business and society research. Business \& Society, 57(1), 3-25.

Davenport, T. H. (2009). How to design smart business experiments. Harvard Business Review, 87(2), 68-76.

Davis, K. (1960). Can business afford to ignore social responsibilities? California Management Review, 2(3), 70-76.

Delmas, M. A., \& Aragon-Correa, J. A. (2016). Field experiments in corporate sustainability research: Testing strategies for behavior change in markets and organizations. Organization \& Environment, 29(4), 391-400.

Eccles, R. G., Ioannou, I., \& Serafeim, G. (2015). The impact of corporate sustainability on organizational processes and performance. Management Science, 60(11), 2835-2857.

Edmans, A. (2012). The link between job satisfaction and firm value, with implications for corporate social responsibility. The Academy of Management Perspectives, 26(4), 1-19.

Eells, R. S. F., \& Walton, C. C. (1969). Conceptual foundations of business. Homewood, IL: R.D. Irwin.

Eisenhardt, K. M., Graebner, M. E., \& Sonenshein, S. (2016). Grand challenges and inductive methods: Rigor without rigor mortis. Academy of Management Journal, 59(4), 1113-1123.

Flammer, C., \& Kacperczyk, A. (2015). The impact of stakeholder orientation on innovation: Evidence from a natural experiment. Management Science, 62(7), 1982-2001. 
Foss, N. J., \& Saebi, T. (2017). Fifteen years of research on business model innovation: How far have we come, and where should we go? Journal of Management, 43(1), 200-227.

Frederick, W. C. (1960). The growing concern over business responsibility. California Management Review, 2, 54-61.

Freeman, R. E. (1984). Strategic management: A stakeholder approach. Boston, MA: Pitman.

Friedman, M. (1970, September 13). The social responsibility of business is to increase its profits. New York Times Magazine.

Gulbrandsen, E. A., Jørgensen, S., Kaarbøe, K., \& Pedersen, L. J. T. (2015). Developing management control systems for sustainable business models. Beta: Scandinavian Journal of Business Research, 29(1), 10-25.

Gulbrandsen, E. A., Jørgensen, S., \& Pedersen, L. J. T. (2017). Sustainability practices and performance in Norwegian knowledge-intensive service companies. Working paper, NHH Norwegian School of Economics.

Harrison, G. W., \& List, J. A. (2004). Field experiments. Journal of Economic Literature, 42(4), 1009-1055.

Jørgensen, S., \& Pedersen, L. J. T. (2015). Responsible and profitable: Strategies for sustainable business models. Oslo: Cappelen Damm Akademisk.

Kang, C., Germann, F., \& Grewal, R. (2016). Washing away your sins? Corporate social responsibility, corporate social irresponsibility, and firm performance. Journal of Marketing, 80(2), 59-79.

Katz, W. G. (1960). Responsibility and the modern corporation. Journal of Law and Economics, 3, 75-85.

Khan, M., Serafeim, G., \& Yoon, A. (2016). Corporate sustainability: First evidence on materiality. Accounting Review, 91(6), 1697-1724.

Kiron, D., Kruschwitz, N., Haanaes, K., Reeves, M., Fuisz-Kehrbach, S. K., \& Kell, G. (2015). Joining forces: Collaboration and leadership for sustainability. MIT Sloan Management Review, 56(3), 1-31.

Levitt, S. D., \& List, J. A. (2007). What do laboratory experiments measuring social preferences reveal about the real world? Journal of Economic Perspectives, 21(2), 153-174.

Levitt, S. D., \& List, J. A. (2009). Field experiments in economics: The past, the present, and the future. European Economic Review, 53(1), 1-18.

Lockett, A., Moon, J., \& Visser, W. (2006). Corporate social responsibility in management research: Focus, nature, salience and sources of influence. Journal of Management Studies, 43(1), 115-136. 
Mont, O., \& Tukker, A. (2006). Product-service systems: Reviewing achievements and refining the research agenda. Journal of Cleaner Production, 14(17), 1451-1454.

Orlitzky, M., Schmidt, F. L., \& Rynes, S. L. (2003). Corporate social and financial performance: A meta-analysis. Organization Studies, 24(3), 403-441.

Selsky, J. W., \& Parker, B. (2005). Cross-sector partnerships to address social issues: Challenges to theory and practice. Journal of Management, 31(6), 849-873.

Solomon, R. C. (1992). Corporate roles, personal virtues: An Aristotelean approach to business ethics. Business Ethics Quarterly, 2(3), 317-339.

Strand, R. (2013). The chief officer of corporate social responsibility: A study of its presence in top management teams. Journal of Business Ethics, 112(4), $721-734$.

Strand, R. (2017). Strategic management in the era of cooperation: Toward a theory of scandinavian cooperative advantage. Unpublished manuscript, University of California-Berkeley.

Sullivan, J., \& Zutavern, A. (2017). The mathematical corporation: Where machine intelligence and human ingenuity achieve the impossible. New York, NY: PublicAffairs.

Tukker, A., \& Tischner, U. (2006). Product-services as a research field: Past, present and future. Reflections from a decade of research. Journal of Cleaner Production, 14(17), 1552-1556.

Waddock, S. A., \& Graves, S. B. (1997). The corporate social performancefinancial performance link. Strategic Management Journal, 18(4), 303-319.

Wang, T., \& Bansal, P. (2012). Social responsibility in new ventures: Profiting from a long-term orientation. Strategic Management Journal, 33(10), $1135-1153$.

Zott, C., Amit, R., \& Massa, L. (2011). The business model: Recent developments and future research. Journal of Management, 37(4), 1019-1042. 
Open Access This chapter is licensed under the terms of the Creative Commons Attribution-NonCommercial-NoDerivatives 4.0 International License (http:// creativecommons.org/licenses/by-nc-nd/4.0/), which permits any noncommercial use, sharing, distribution and reproduction in any medium or format, as long as you give appropriate credit to the original author(s) and the source, provide a link to the Creative Commons license and indicate if you modified the licensed material. You do not have permission under this license to share adapted material derived from this book or parts of it.

The images or other third party material in this chapter are included in the chapter's Creative Commons license, unless indicated otherwise in a credit line to the material. If material is not included in the chapter's Creative Commons license and your intended use is not permitted by statutory regulation or exceeds the permitted use, you will need to obtain permission directly from the copyright holder.

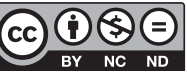

